\title{
Renegotiation Of Waste Disposal Services In Key West, Florida
}

Annalise Mannix, Hodges University, USA

Val Candy, Capella University, USA

Donald A. Forrer, Hodges University, USA

\begin{abstract}
Effective planning of a solid waste recycling program is a substantial challenge for the current waste management system in Key West, Florida. Solid waste management strategies have to be reorganized in light of the social and economic recycling, recovery, and reuse philosophical approaches which are dramatically changing consumer behaviors across the globe. The growing concern for environmental issues and the goal of local sustainable development have moved the management of solid waste to the forefront of the public agenda. This paper focuses on efforts to agree upon a city-wide initiative to increase waste diversion within the prevailing political, environmental, and economic climate in which waste disposal activities had dominated the market. It discusses how the traditional two-party solid waste hauling contract was altered by the addition of outside third-party interests forcing a multi-party negotiation processes.
\end{abstract}

Keywords: Waste Treatment; Waste Disposal; Waste Management; Key West; Renegotiation; Green; Political; Strategic Plan

\section{BACKGROUND: HISTORICAL PERSPECTIVES}

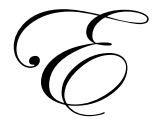

ffective planning of a solid waste recycling program is a substantial challenge for the current waste management system in Key West, Florida. Solid waste management strategies have to be reorganized in light of the social and economic recycling, recovery, and reuse philosophical approaches which are dramatically changing across the globe. The growing concern for environmental issues and the goal of sustainable development have moved the management of solid waste to the forefront of the public agenda. Legislation and regulations, along with techniques for appropriate waste treatment and disposal, have been introduced in local and national levels to improve waste management systems. Moreover, strategies for sustainable waste management have emphasized the need to minimize waste production, increase waste recovery, and reduce the use of landfills. Managers of municipal recycling programs must balance citizens' demands for more efficient services within budget with state-mandated performance measures while ensuring compliance with federal regulatory bodies.

\section{The Problem}

The City of Key West's local government staff, City Commissioners, and ultimately tax- paying citizens and voters, have been faced with intense and long-drawn out negotiations with representatives of several organizations seeking to promote the tangible and intangible interests of various constituent groups with conflicting, yet overlapping, missions. Each organization claims to offer greater overall value than the traditional contractor, Waste Management, which, for decades, has held a virtual monopoly on this lucrative service. The City's organizational and strategic plan for doubling recycling rates from 2010 to 2015 throughout its jurisdiction had been based on historic solid waste inventory, current waste volumes, and projections provided by the City Climate Action Team and is tied to cost savings associated with decreased solid waste haul-out costs required due to the geographical nature of the island city. Following the City's membership of the International Community of Local Environmental Initiatives (ICLEI) in 2009, a more open market and bottom-up approach to sustainability planning, and therefore negotiations for all contracts contributing to a sustainable future, is being considered to meet the underlying interests of a green-conscious community. In Key West, this community continues to gain momentum 
and political power, although it frequently clashes with Waste Management on several areas of policy and procedure as the two compete rather than collaborate. National and local experts agree that much work still needs to be done to navigate through the complexity of all the issues regarding equity, fairness and distribution of the costs of implementing a waste diversion and carbon reduction program in Key West.

Theories of negotiation and political scientists distinguish between two types of bargaining in broad terms by defining distributive bargaining as that used under conditions where parties seek to divide a "fixed-pie" with whoever increases her or his relative gain or share, usually at the expense of the other party. Outcomes are sometimes decided in an arbitrary manner and will favor some over others (Raiffa, 1982). However, under conditions of integrative bargaining, parties are more cooperative and endeavor to make the pie larger so that both or all parties have a bigger share (Young, 1994). Outcomes are decided in a principled manner, are likely to be fair and equitable, and will favor both or all parties. The City's (Key West) Climate Action Plan (CAP) aims to maximize the benefits of such principles by use of the City's core competencies, intermediaries, and distribution channels while remaining loyal to its mission to protect the citizens and habit of Key West. This paper focuses on efforts to agree upon a city-wide initiative to increase waste diversion within the prevailing political, environmental, and economic climate which is threatening Waste Management's bottom-line. It discusses how the typical two-party solid waste hauling contract was altered by the addition of outside third-party groups and multi-party negotiation processes.

\section{LITERATURE REVIEW - GLOBAL NEGOTIATIONS}

The United Nations Framework Convention on Climate Change (UNFCCC) was adopted at the United Nations Conference on Environment and Development in Rio de Janeiro as long ago as 1992. Today, even in the average household, the topic of climate change inspires passionate and heated debate despite the rapid advances afforded by ongoing research and scientific uncertainties. Although the science and politics of climate change are more than a century old, the systematic approach to tackling its yet unknown impact may be traced back to the 1988 Toronto Conference on "The Changing Atmosphere: Implications for Global Security" and the Montreal Protocol through which the suggestion to create a series of international conventions to discuss the climate regime was proposed (Ramakrishna, 1992, p. 3). Ironically, at that time, while the United States was among those nations which considered this to be an implausible target, Washington D.C. hosted the first negotiating session on the subject three years later (in 1991). The United States was also one of the first major nations to ratify the convention bowing to pressure from institutional innovation and, in particular, the Inter-governmental Panel on Climate Change (IPCC) which was formed by the World Meteorological Organization and the United Nations Environment Program (Grubb, 1999). This opening negotiation session emphasized the IPCC's scientific nature and overall mission to help 160 member countries measure, standardize, gather, and disseminate atmospheric data.

The Panel formed three working groups to: 1) assess the available scientific information on climate change, 2) assess the environmental and socio-economic impacts of climate change, and 3) formulate response strategies. The objectives of the groups called for a balance which would achieve stabilization of greenhouse gas concentration in the atmosphere within a time frame which would also allow ecosystems to adapt naturally to climate change, ensure that food production would not be threatened, and enable economic development to proceed in a sustainable manner (Cohen et al.,1998). The Rio Summit of 1992, which discussed the combined energy of industrialized nations, included Articles which acknowledged Parties' (individual nations) different starting points and approaches, economic structures and resource bases, the need to maintain strong and sustainable growth, available technologies, and the need for equitable, yet appropriate, contributions to reach global or common targets. In addition, the articles made provision for parties to implement policies and measures jointly with other parties in contributing to achievement of the global targets. During these meetings, the industrialized countries, led by the United States, argued that despite the clause that had been adopted in 1992 for "equal but differentiated responsibilities" between developing and developed countries, it was essential for developing countries to join the next phase of commitments (Tangen, 2005). President Bill Clinton launched the White House Initiative on Global Climate Change that same year in anticipation of the Kyoto Protocol, which was not adopted until December 11, 1997, after eleven days of intensive negotiations.

It was the Kyoto Protocol that finally paved the way for legally binding emission commitments calculated as an average over the period 2008-2012 with targets ranging from 8 percent to 10 percent. However, the U.S. 
Senate had serious reservations and passed a non-binding resolution, the Byrd-Hagel Resolution, which restricted the President's negotiating position since it had resolved that any new commitment signed by the U.S. President would also have to be met by a scheduled commitment of developing countries. In addition, any agreement would have to be ratified by the Senate following a detailed explanation and review and that no agreement would be ratified if it could harm the U.S. economy (Hohne \& Blocke, 2005). A series of Conventions of Parties (CoPs) have since taken place at venues across the globe, starting with the Berlin Mandate (CoP 1) in 1995 through to the UN Framework on Climate Change Conference in Mexico (CoP 16) December, 2010. Waste diversion is one method to reduce carbon emissions. It has specifically identified by the $\mathrm{EU}$ as an important principle to carbon dioxide (CO2e) reduction.

\section{Two-Level Games and Coalitions}

Negotiation is "a process in which two or more entities come together to discuss common and conflicting interests in order to reach an agreement of mutual benefit" (Harris \& Moran, 1987, p. 55). The environmental debate on matters, such as controlling climate change and emissions of greenhouse gases, protection of the ozone layer and biodiversity, are global in the sense that they cannot be managed effectively in isolation, but that they require international coordination of individual nations' policies (Mayer, 1992). According to Putman (1988), domestic and international politics are so inextricably linked that the politics of many international negotiations are akin to a twolevel game through which the two negotiators seek to build a package or bargaining mix that will be acceptable to both the other side and the domestic bureaucracy. Frequently, what may be a rational move to satisfy a home constituency may be considered an undiplomatic move by the other international negotiator participating in the game. Mariotti (1997) examined the strategic nature of the role of international institutions in achieving International Environmental Agreements (IEAs) and concluded that such institutions can influence the outcomes of negotiating countries by setting the rules or the protocol for negotiations and by selecting the most desirable agreement based on cooperative or non-cooperative tactics of each nation. The authors concluded that some nations would prefer to adopt a non-cooperative strategy which would minimize the cost of domestic compliance while freeloading on other nations who reach agreement through a more cooperative frame.

Singh (2000) examined the extent to which developing countries are influencing outcomes from a bottomup approach by negotiating in scenarios governed by pragmatic rules, such as trade-offs, coalition building, lobbying in other countries, and agenda setting rules, rather than in power structures where the developed countries had traditionally set the rules in an authoritarian or confrontational manner. Theories of negotiation and political scientists distinguish between two types of bargaining in broad terms by defining distributive bargaining as that used under conditions where parties seek to divide a "fixed-pie" among themselves with whoever increases her or his relative gain or share doing so at the expense of the other party. Outcomes are decided in an arbitrary manner and will favor some over others (Raiffa, 1982). Under conditions of integrative bargaining, parties are more cooperative and endeavor to make the pie larger so that both or all parties have a bigger share (Young, 1994). Outcomes are decided in a principled manner, are likely to be fair and equitable, and will favor both or all parties.

Humpheys (2000) reviewed three rounds of international negotiations in relation to bargaining theory and the distributive/positional approach where parties view each other as adversaries claiming value or the integrative/principled approach where parties consider each other to be partners working together to address a common problem. He argued that the latter form of bargaining was based on fair standards where the negotiation is seen more as a positive sum-game, whereas issues which were more contentious and politically charged were more distributive. Humphreys concluded that a shift from distributive bargaining to integrative bargaining takes place as the result of expansion of the agenda where more new issues could reach common ground.

\section{Local Government Initiatives}

The International Conference on Local Environment Initiatives (ICLEI) included over one hundred references to local government initiatives; however, the perspectives from developed and developing countries are quite different in terms of what was achieved during negotiations at a national and international level. Some researchers claim that the failure to sign a legally binding treaty is advantageous to ensuring that radical alternatives are considered rather than locking the world into flawed principles and processes whereby emitters, rather than 
producers of carbon emissions, are required to clean up their carbon footprint (Sherwell, 2009, p. 6). Researchers are concerned with the processes pursued to reach agreement which undermine the fundamental rule of multilateralism in international negotiations; that is, transparency and inclusiveness.

Coram (2003, p. 174) further adds to the complexity by introducing the concept of "value" and suggests a quantifiable amount should be attached based on the perceived value to individual producers and/or emitters. Furthermore, Coram argues that value may be attached through a process based on comparison involving stand alone, buyout, rent, or compensation (p. 177). Fagan (2004) claimed that waste is a "global fluid, but it is usually invisible, deemed unproductive, and certainly not well-researched" (p. 87). Importantly, Fagan claims that in the global economy, deregulation and free-market forces should dominate waste diversion since traditional policies and procedures have failed in their attempts to create a sustainable future (p. 87). Such a position opens the door for debate about "time space-compression and the information society" which have created a new network state of shared institutions enacted through an ongoing process of bargaining along the decision-making chain from supranational to local government and non-government organizations (NGOs) - not necessarily a mechanistic decision-making process previously practiced by local governments. Hence, local government boundaries are increasingly blurred in negotiating waste management contracts or smaller potential suppliers seeking to fill niche markets by providing more specialist services for the green conscious consumer. This means a balance needs to be struck in attending to the needs of individual stakeholder groups while also creating value for the majority of consumers.

There is also a risk that voices of dissent may be marginalized while the interests of only the societal elite are served since they engage in the loudest form of irrational resistance to dumping locally or, as it is known in the trade "Not in My Back Yard" (NIMBY) or "Build Absolutely Nothing Anywhere Near Anything" (BANANA)", regardless of the available technical knowledge dismissing fears and supporting such practice (Murray, 2009, p. 83). Governments are responsible for framing the issue of local waste disposal and diversion as either irrational or selfish since they tend to define objections from citizens as NIMBY (Murray, p. 96). Pressure and competition is the key to operating more efficiently and cities often contract for a range of services where waste disposal is the area through which the greatest cost savings may be seen, although outsourcing garbage services creates an opportunity for corruption (Morgan, 1986, p. 58). To ensure greatest value for money in contracting waste diversion and disposal services, some cities have managed waste inventories to better inform what services are required to serve the citizens and have engaged public relations programs to target solutions (Mafrici, 1971, p. 2010).

The complexity and dynamics of urban evolution have created difficulties in the management and maintenance of quality of life. Traditional planning systems based on transitional short-term policies are struggling to meet current demands. For the purposes of this paper, municipalities may be compared to small and medium businesses when adopting green practices. Where environmental uncertainty prevails (unpredictable changes in customer preferences, technological development, and competitive behavior perceived by managers), smaller organizations fail to take on green initiatives due to lack of financial and knowledge capital. The goal of sustainability is opening the door to newer approaches to the management of municipal solid-waste, and the two most notable and measurable outcomes are environmental and financial in nature.

Hostovsky (2005, p. 81) discusses the drawbacks to prolonged fact-finding negotiations in the Provence of Ontario which failed to reach an agreement for local waste disposal after 17 years of bargaining at a cost of $\$ 23$ million. However, this failure created so much publicity that it unwittingly encouraged greater creative problemsolving and community recycling as a byproduct. Today, Ontario recycles 60 percent of its waste rather than using traditional waste disposal methods and it exports the remaining 40 percent to the United States.

Waste diversion is an important method of reducing $\mathrm{CO} 2 \mathrm{e}$ for local governments and the US, state and local governments are all attempting to negotiate acceptable and cost effective solutions to our increasing waste problem. 


\section{Key West Local Initiatives and Negotiations}

Key West has a population of about 24,630 permanent residents. It is highly influenced by the tourism and hospitality industry and subject to large seasonal fluctuations in the number of inhabitants and workers, often doubling the population as they strive to meet supply and demand. The City of Key West Strategic Plan (2011) establishes priorities and concerns based on input from its citizens. The planning document seeks to complete its initiatives in five years and targets environmental management elements, such as "responsible consumption and disposal of all natural and manmade resources."

The City of Key West's Plan for Sustainability: A Plan for the Environmental Stewardship of Key West (2008) was written following extensive consultation with citizens and members of the business community over many years to address identified environmental issues that pose a threat to the environment if left unmonitored. The Sustainability Plan is based on resolutions, plans and goals already established by the City of Key West or the state of Florida. Within this context, Key West defines sustainability as "stewardship of local and imported resources in balance with the needs of the community so that there is no resultant net environmental loss for future generations. Key West's mission statement for the sustainability is "to enjoy and preserve paradise, its wildlife and environment for generations to come".

According to the City Manager's Office, there are about 13,000 non-commercialized single-family dwellings (SFDs) or property owners who pay a fixed annual fee of $\$ 300.31$. Recycling services are included as part of the overall service (\$3.00). According to the Occupational Licenses department, there are approximately 600 businesses within the city limits which pay for individual disposal of waste based on volume with recycling services drawing a supplemental fee again based on volume. Existing waste diversion and recycling is contracted to Waste Management which has enjoyed a virtual monopoly on services provided since the city decided to limit commercial and residential disposal to one company in the 1990's. Associated contractual costs have rarely been seriously challenged by city staff negotiators. Traditionally, Waste Management's business strategy has been to maximize disposal at the lowest cost.

Garbage provides a snapshot of what is really going on in a community. Because Key West is the gateway to major tourist destinations in the Florida Keys, the City of Key West and other local authorities are very concerned with land-usage and the aesthetic appearance of the streets, beaches, residential and non-residential divisions alike. The city's resources are faced with the challenges of growth, economic instability and balancing a "unique" way of life with quality of life. The consequences of global climate change is very real in Key West and the demands placed on virtually finite natural resources are depleting them faster than they can be reasonably expected to regenerate. As a government entity, the City of Key West plays a critical role as both consumer of the present and architect of the future. To ensure sustainability, it needs to adopt strategies for shifting collective behavior of city operations and citizens. Saving resources, land, and money needs to be a high ranking priority for planning purposes, in general.

Key West has the opportunity to make a major change in its recycling program, which will also help in achieving the city's goal of reducing carbon emissions. The existing recycling program has been stagnant or failing for many years and the current management process is not working well. However, following much publicity and education aimed at increasing awareness of environmental issues, a significant and vocal sub-community, comprised of lobbyists, activists, and the general population, has set the scene for greater sustainability and waste diversion by demanding that elected officials consider alternative organizations and local businesses as a means of forcing the green issue as a viable alternative. In other words, this community defines value as the method through which waste diversion rates and activities increase while reducing waste disposal rates. To date, the relationship between Waste Management International (WMI), the city's waste hauler, and the green community has been somewhat antagonistic with both parties seeking to claim value through distributive bargaining rather than attempting to explore underlying interests through which value and synergy may be created for the citizens at large.

Jehn and Mannix (2001) studied group performance and the dynamic nature of conflict, reporting that their results indicated that in the middle and late period of group work, consensus was negatively associated with conflict and that relationship and process conflict were associated with low levels of respect and cohesiveness, while task conflict was associated positively with discussion norms. 
In multi-party negotiations, it is important for each party to voice deviant views, which enhances creativity and allows for increased options for settlement. Nemeth (1986) points out that argument from the minority view stimulates the productive thought process, while from the majority creates a convergence of thoughts. People tend to take the path of least resistance, so arguments and alternative do not necessarily receive scrutiny. This managing the negotiation process in multi-party situations is vital to sustain an integrative bargaining protocol.

Theories of negotiation and social scientists suggest there are two broad types of bargaining - distributive and integrative. Distributive bargaining, which is used under conditions where parties seek to divide a "fixed-pie" with whoever increases her or his share, doing so at the expense of the other party or parties. Often outcomes are decided in an arbitrary manner and will favor some over others (Raiffa, 1982). In integrative bargaining, parties are more cooperative and the goal is to make the pie larger so that all parties have a bigger share (Young, 1994).

Legitimate, position-based, or contextual power is a key determinant in any negotiation and helps derive the party's best alternative to a negotiated agreement (Fisher, Ury, \& Patton, 1991). When the values of the BATNA are high, the less needy the party is to reach an agreement, the fewer concessions it needs to make, and the more risks it can take, including waiting out the other side. Fisher et al. argue that if it is abusive, it removes an incentive for others to negotiate; it can also be used to make concessions to weaker parties over a continued state of conflict on unequal terms.

In a study of three-party mixed motive negotiations, Kim (1997) argued that where parties do not share equal opportunity to engage in discussion, those excluded received a smaller share. Kim found groups that excluded the lower power parties had less integrative solutions than those groups that maintain negotiations or exclude the higher power parties.

In past waste management contracts, the City of Key West negotiated with various vendors in a more distributive bargaining manner, with the city desiring the best price and negotiating using hardball techniques to get the best price. The city owned its own landfill and waste-to-energy plant. The city had contracted with Industrial Waste Services in 1991 and Bering Ferris Industries bought out the contract in 1995 for a curbside solid waste and recycling collection franchise contract. After ten years, the city sought a new vendor and selected WMI. The waste vendor was seeking to gain a client, perhaps with less than preferred profitability, in order to increase market share in the municipalities along the chain of the Florida Keys.

The tides changed over the past 20 years as WMI convinced the city to limit commercial competition and have only one commercial hauler as was the practice with the residential market. In addition, the landfill met its permit volume and was closed, and the City contracted with a trucking firm to haul the ash residue to a Broward County landfill. Later, a NIMBY push by residents adjacent to the waste-to-energy power plant, seeking to limit industrial properties in the area, asked the city to close the facility rather than upgrade to meet new environmental regulations. The city deliberated extensively on options since the long-term financial outlook for maintaining the plant was more economically feasible than hauling trash to the mainland. WMI offered the city very reasonable rates to haul trash to their Broward County waste-to-energy plant, which clinched the deal, and against the recommendation of the utility staff, the city fathers, who were looking to honor their constituent request, authorized the removal of the plant. This action turned the tides of power in all future contract extensions and future bids as WMI was now the sole residential and commercial waste and recycling curbside vendor, inter-county waste hauler, and operator of the Broward waste-to-energy facility and holds the contract with Broward County for ash and waste disposal at the landfill. WMI now completed its hand and holds all the cards, leaving the city in a less desirable negotiating position. WMI is now in a position to use more distributive bargaining over price and services where the city will have to work to use a more integrative approach.

Negotiation is "a process in which two or more entities come together to discuss common and conflicting interests in order to reach an agreement of mutual benefit" (Harris \& Moran, 1987, p. 55). In Key West, the desire for more updated waste management services caused a need for multi-party negation in which multiple parties work toward a collaborative objective, which adds a level of complexity that increases with the number of parties. According to Lewicki, R., Saunders, D., \& Barry, B. (2011), information and computational, social, procedural and strategic complexity increases as the parties in a negotiation increase. 
Green groups united due to a desire for green waste management processes that offer significant opportunities to divert waste from disposal. Low recycling rates and perceived poor recycling service from the city's vendor of 10 years left rate payers with reduced trust in the current vendor. The city did not openly seek different perspectives on its programs; however, the green community constantly provided information and perspective to enhance the bargaining mix for the upcoming expiring contact.

The city desired to extend the existing standard waste contract because of favorable rates and acceptable levels of service. The city had a long-term relationship with WMI and even longer term with the local Service Manager. As their position of power was reduced, the city could not expect favorable rates on contract changes. WMI desired to maintain the existing contract but, due to public grumblings, expressed a desire to improve recycling services through use of larger 60-gallon roll-out recycle containers, which is proven to increase rates in communities. This would not increase their equipment usage nor labor significantly. The city would, however, have to purchase the new containers at the cost of $\$ 130$ for each of 12,000 or so residential and small multi-family units (16 units and less).

The green community helped elect members of the City Commission and continuously garnered increasing support of the general community through news articles, letters to the editor, editorials, opinion forums, community meetings, special events such as recycling fairs and eco-weekends, and by attending en masse televised City Commission meetings. They claimed that the community needed to look at waste from a whole new perspective and consider waste a commodity rather than a waste product. Due to perceived distrust of WMI, which was based on some perceived mishandling of recycling as well as perceived misinformation provided by WMI staff, many in the general community expressed a desire to obtain a new vendor with new ideas; hence, they claimed lack of knowledge of the recycling program and commercial recycling fees were barriers to commercial and residential recycling within the city.

One green non-profit, with a very focused approach, partnered with a second environmental community non-profit and hired a professional waste consultant to present the state-of-the-art in alternatives to land filling and incineration. The presentation enhanced City Commission support of alternatives to haul trash 150 miles. Also, the consultant met with the County Manager to discuss opportunities for the city and county to partner in waste proposals.

The WMI contract could be extended for a final five years, which, if extended 'as is', would limit the proposed changes the community desired. The city took a no-agreement approach, ignoring the reminders from the waste vendor.

WMI waited, knowing that the city was less and less likely to go out to bid as time passed. The city currently has no waste landfill, no waste-to-energy facility, and has no garbage trucks, making it difficult for them to allow a week's interruption in the contract. As the "no agreement" approach was not going to work due to green persuasion, the impasse alternatives became clear - a third party would be used to provide "real" data and analysis and help solidify the near-term orientation for the city. Lewicki et al. (2007) argue that groups with better impasse alternatives tend to fare better than others. In this case, WMI had a perfect impasse alternative due to the late start of formal negotiations.

Finally, to avert a last-minute catastrophe by not having an RFQ out on the street (takes months of planning for a waste hauler to come in and take over a city's system - especially on an island 140 miles from the closest landfill an no contracted waste facility), staff brought the green community and WMI together to negotiate a "first agreement". This interim solution would allow for a modest approach by the city, extending the contract extension negotiating a clause to allow further modifications as the city desired to implement changes to the waste process. The city agreed to hire a consultant to make recommendations over the next few years. They hired Kessler Consulting, Inc. which was tasked to develop a Solid Waste Master Plan for the city to be used to identify near-term an longer-term recommendations to enhance material recovery and waste diversion.

The cost and agreeability of those changes would be further re-negotiated through the next five years of the contract with each tweaking of service. Waste Management agreed to continue with just a consumer price index 
adjustment annually and negotiate changes as necessary. The final agreement will include a five-year contract with a new RFQ at the conclusion of the existing contract and no further opportunities for extension. According to Lewicki, et al. (2007), first agreements typically support the majority of a multi-party negotiation, so the dissenting group - the green community - will be required to ensure they do not get cut out of further negotiations.

\section{The Negotiation Stage}

The pre-negotiation stage was characterized by a crescendo of public input on a variety of green issues, all of which helped point to solid waste as the simple first steps the city could adopt. Waste management proposed the use of new larger recycling containers, offered to add groups of recyclable plastics to the pick-up, and to replace the old 13-gallon bins with 60-gallon roll-out containers.

The city sought to budget the desired solid waste management consultant. The key participants in the negotiation were the vice president of the green organization, the local Service Manager of Waste Management and the City Utility Manager, who mostly met individually with the other parties, and the results were negative until it was clear that the Green constituency was serious about having a stake in the negotiation process. Staff initially did not bring the green group to meetings possibly due to the opportunity for them to be veto players or coalition blockers; however, the green coalition's position was greatly increased as they were recommended by members of City Commission, the community at large, and eventually staff. As their power increased their presence in the negotiation process, they played a task-oriented role informing, evaluating, coordinating and energizing the process.

\section{CONCLUSION}

Although conflict is expected and a normal part of the negotiation process, if poorly managed, the process is compromised. Jehn and Mannix (2001) reported, "High performing teams were characterized by low but increasing levels process conflict, low levels of relationship conflict with a rise near the deadline, and moderate levels of task conflict at the midpoint of group interaction (p. 239). At this point, it is recommended that the city work with the negotiator to measure their conflict profile and work to develop more effective strategies for dealing with conflict in the future as recommend by Jehn. They need to develop trust, respect, and begin an open dialog to enhance future second-agreement negotiations. The green groups are seeking composting alternatives and re-use of yard and tree debris. This contributed approximately 30 percent of the City's waste. These new options may be able to sustain a number of full-time jobs in Key West and significantly reduce the number of trucks filled with waste being hauled to WMI facilities in Broward County which release carbon emissions. The competition that this may bring should be good for the city. Morgan (1986, p. 58) found that cities that had competition, even if it was city-run curbside waste hauling, obtained favorable pricing compared to those cities where no competition exists. He suggests that competition is barrier to corruption and collusion.

Nemeth (1986) suggests that people tend to take the path of least resistance in order to ensure that arguments and alternatives do not necessarily receive scrutiny. Thus, managing the negotiation process in multiparty situations is a key issue to sustain an integrative bargaining protocol which can open the doors to a larger "pie" for Waste Management and praise for the city for meeting the goals of the Climate Action Plan. It is recommended that the green groups ensure they remain in negotiations throughout the process to endure an integrative solution (Kim. 1997).

\section{AUTHOR INFORMATION}

Annalise Mannix is a Florida Licensed Professional Engineer, and the principal engineer of Annalise Mannix Engineering and Consulting, LLC, specializing in site planning, residential and commercial structures and climate change mitigation and adaptation planning. A graduate of New York's Maritime College she is currently pursuing a Master's degree in Management with Hodges University. E-mail: amannix@aol.com.

Valerena U. Candy graduated from Hodges University and is currently pursuing a $\mathrm{PhD}$ in Management. Additionally, she has co-authored several public policy documents including the City of Key West's adopted Climate Action Plan, and the Best Practice Research Scholarships for Teachers in the United Kingdom. E-mail: ValCandyMS@aol.com. 
Donald A. Forrer has a Doctorate in Business Administration and serves as a Professor in the MBA/MPA program at Hodges University (formerly International College) of Naples, Florida. Additionally, Don is the CEO/President of Cybernetic Concepts, a management consulting team specializing in utility economics. E-mail: dforrer@hodges.edu. Corresponding author.

\section{REFERENCES}

1. City of Key West. (2009). Climate action plan. Retrieved June 15, 2011 from http://www.keywestcity.com

2. City of Key West (2011) Strategic Plan. Retrieved June 28, 2011 from http://www.keywestcity.com

3. City of Key West (2008) Plan for Sustainability: A Plan for the Environmental Stewardship of Key West. Retrieved June 28, 2011 from http://www.keywestcity.com

4. City of Key West Solid Waste contract Retrieved August 12, 2011 from http://www.keywestcity.com

5. City of Key West. (2011). 2010/2011 Waste composition study Retrieved August 22, 2011from http://www.keywestcity.com

6. Cohen, S., \& Eimicke (1998). Tools for innovators: Creative strategies for managing public sector organizations. San Francisco, CA: Jossey-Bass.

7. Cohen, S., Demeritt, D., Robinson, J., \& Rothman, D. (1998). Climate change and sustainable development: Towards dialogue. Global Environmental Change, 8, (4), 341-371.

8. Coram, A. T. (2003). Maintaining environmental resources in the international system: A comparison of contractual arrangements. Social Science Quarterly, 84(1), 175-190.

9. Fagan, G.H. (2004). Waste Management and its Contestation in the Republic of Ireland. Capitalism Nature Socialism, 15(1), 84-102.

10. Fisher, R., Ury, W. \& Patton, B. (1991). Getting to yes: Negotiating without giving in. $2^{\text {nd }}$ Ed.

11. R. Grubb, M. (1999). The Kyoto Protocol: A guide and assessment. Earthscan, London.

12. Harris, P. R. \& Moran, R. T. (1987). Managing Cultural Differences, $2^{\text {nd }}$ ed., Gulf Publishing Company, Houston, TX.

13. Hohne, N., \& Block, K. (2005). Calculating historical contributions to climate change. Climate Change, 71,(2), 141-173.

14. Hostovsky, C. (2005). Evaluation in integrated waste management: Understanding the crisis and improving practice through planning theory. Canadian Journal of Urban Research 14(1), 81-101.

15. IPCC. (2007). Fourth assessment report of climate change. The Physical Science Basis, Cambridge University Press, Cambridge.

16. Jehn, K. A., \& Mannix, E. A. (n.d). The dynamic nature of conflict: a longitudinal study of intragroup conflict and group performance. Academy of Management Journal, 44(2), 238-251.

17. Kim, P. H. (1997). Strategic Timing in Group Negotiations: The Implications of Forced Entry and Forced Exit for Negotiators with Unequal Power. Organizational Behavior \& Human Decision Processes, 71(3), 263-286.

18. Lewicki, R., Saunders, D., \& Barry, B. (2011). Essentials of negotiation ( $5^{\text {th }}$ ed.). New York, NY: McGraw-Hill.

19. Lewicki, R., Saunders, D., \& Barry, B. (2011). Readings, exercises, and cases $\left(6^{\text {th }}\right.$ ed.). New York, NY: McGraw-Hill.

20. Lin, C.Y., \& Ho, Y. H. (2010). The influences of environmental uncertainty on corporate green behavior: An empirical study with small and medium-size enterprises, Social Behavior and Personality 38(5), 691696.

21. Mafrici, D. (1971). The role of the local health department in solid waste management. American journal of public health 61(10), 2010-2014.

22. Mayer, F. (1992). Managing domestic differences in international negotiations: The strategic use of internal side-payments. International Organization, 46, 793-818.

23. Mariotti, M. (1997). A model of agreements in strategic form games. Journal of Economic Theory, 74, 196217.

24. Morgan, D. R. (1986). Cost and competition. Society, 54-61

25. Murry, M. Waste management in Ireland: discourses of domination in an (un)reflexive society. The Sociological Review, 57(1), 82-101. 
26. Nemeth, C. J. (1986). Differential contributions of majority and minority influence. Psychological Review, 93(1), 23-32.

27. Putman, R. D. (1988). Diplomacy and domestic politics: The logic of two-level games. International Organization, 42, 3.

28. Raiffa, H. (1982). The art and science of negotiation. Harvard University Press, Cambridge.

29. Ramakrishna, K. (1992). The UNFCCC: History and evolution of the climate change negotiations. Woods Hole Research Center. MA, USA.

30. Snyder, G. H., \& Diesing, P. (1977). Conflict among nations: Bargaining, decision making, and system structure in international crises. Princeton University Press.

31. United Nations Framework Convention on Climate Change. (1995). Addendum 1(actions taken) to report of CoP1, Berlin.

32. United Nations Framework Convention on Climate Change. (1997a). Addendum 1 (proposals for a protocol or another legal instrument) to report of AGBM6, Bonn.

33. United Nations Framework Convention on Climate Change. (2009). Copenhagen accord

34. Retrieved June 15, 2010 at http://unfccc.int/files/meetings/cop_15/application/pdf/cop15_cph_auv.pdf

35. United States Trade and Industry Report. (2005). Participation, power, partnership: Seeking sustainable results through U.S. trade capacity building.

36. Vaughan, A., \& Adams, D. (2009, December 22). Copenhagen climate deal: Spectacular failure or a few important steps. The Guardian, p. 12.

37. Young, O., R. (1994). International governance: Protecting the environment in a stateless society. Cornell University Press, Ithaca. 